\title{
edmetic
}

Revista de Educación Mediática y TIC

\section{El estado de la cuestión III: Binomio Educación y TIC hoy}

El auge de las tecnologías de la información y la comunicación, como ya hemos señalado en diversos foros es inigualable. La realidad digital del día a día implica que su presencia no pueda ser obviada, así en las esferas centrales de la vida del sujeto juegan un papel cardinal.

Centrándonos en el ámbito educativo y como sostenían no hace mucho tiempo Akçay y Arslan (2010), hablar en estos momentos de un sistema educativo, independientemente del nivel en que nos situemos, sin las TIC es inimaginable La introducción de las TIC en los procesos de aprendizaje han ido produciendo una nueva forma de enseñar y de aprender tanto en su vertiente teórica como en la práctica (Jari, Näykki y Järvelä, 2012).

Si bien compartimos con Gómez-López y Cano (2011) que la implantación de las TIC en los centros educativos es compleja, por el gran número de cambios en los que estos se ven inmersos, en el caso de la enseñanza puede ser entendida como un elemento renovador del propio proceso de enseñanza-aprendizaje como indican Correa y Paredes (2009). La formación tecnológica de los estudiantes es una necesidad, más que una realidad, es por ello que habrá que desarrollar en ellos una capacitación digital que les ayude en la búsqueda, selección y transformación de la información que encuentran en la red Internet (Marín, 2011).

Este tercer monográfico dedicado a las experiencias de uso de las TIC centradas en el ámbito educativo, es prueba de la relevancia que está teniendo para las fuerzas educativas esta imbricación. 
Bibliografía

AKÇAY, A. Y ARSLAN, A. (2010). The using of blogs and Turkish education. Procedia Social and Behavioral Sciences, 2, 1195-1199.

CORREA, J. M., Y PAREDES, J. (2009). Cambio tecnológico, usos de plataformas de e-learning y transformación de la enseñanza en las universidades españolas: la perspectiva de los profesores. Revista de Psicodidáctica, $14(2), 261-278$.

GÓMEZ-LÓPEZ, J., \& CANO ESCORIAZA, J. (2011). El pensamiento docente y su influencia en la implantación de las tecnologías de la información y la comunicación en el aula: desafíos y oportunidades. Contextos Educativos, 14, 67-83.

JARI, L., NÄYKKI, P., Y JÄRVELÄ, S. (2012). Supporting small-group learning using multiple web 2.0 tools: a case study in the higher education context. Internet and Higher Education, 15, 29-38.

MARÍN, V. (2011). Trabajando en el aula de Grado de Educación Primaria con Edublog. En G. Domínguez, E. López y A. H. Martín (coords.). II Seminario científico sobre formación, estrategias didácticas y experiencias digitales 2.0 en el Espacio Europeo de Educación Superior. (pp. 193-205). Sevilla: Ed. AFOE.

Verónica Marín Díaz Editora Revista EDMETIC; Revista de Educación Mediática y TIC vmarin@uco.es 